\title{
Transport Sustainability Performance Evaluation using a Multi-stage Multi-tool Hybrid Model
}

\author{
Ubaid Illahi $^{1 *}$, Mohammad Shafi Mir ${ }^{1}$ \\ ${ }^{I}$ Transportation Engineering \& Planning Division, Department of Civil Engineering, National Institute of \\ Technology Srinagar, Hazratbal-190006, Srinagar, Union Territory of Jammu \& Kashmir (India)
}

\begin{abstract}
This article proposes a multi-stage and multi-tool hybrid model (MMHM) for evaluating the performance of transportation systems. This model is based on pillars, classes, and indicators. The novelty of MMHM is that the indicators were weighted at three different levels using Principal Component Analysis, Fuzzy Logic, and method of equal weights. The output of the MMHM is an index called Sustainable Mobility Index (SMI). SMI gives the relative performance of transportation systems. MMHM was applied to four metropolitan cities of India. A total of 116 indicators were developed that were divided into ten classes, each corresponding to three sustainability pillars. The results demonstrated that MMHM is useful in ranking the study areas. It also demonstrated that it could be a valuable tool to recognize, track and evaluate the sustainability performance of transportation systems which would be beneficial to transportation evaluators, planners, decision-makers, and policymakers.
\end{abstract}

Keywords: sustainability, indicators, index, transport evaluation, transport planning

\section{Introduction}

Mobility is the lifeblood of society, as it promotes people's holistic growth and wellbeing. It provides people with access to employment, goods, and services, improving their economic condition. This, in turn, improves the prosperity within the society. However, sustaining this has become challenging due to several reasons. For example, transportation is one of the most significant and rapidly increasing sources of emissions in the world. Moreover, there are huge losses of resources, both in terms of precious lives as well as economic losses due to traffic crashes. Therefore, it would not be wrong to call transportation a necessary evil. According to the 2030 Agenda, achieving resilience in transportation systems is one of the top priorities for the next decade. This requires optimization of the transport systems so that the damaging effects are curtailed while exploiting the progressive impacts. Stakeholders and other investors can help assess the diverse and multifaceted challenges that the transportation industry faces in order to meet its priorities and objectives by approaching transportation sustainability from a holistic

*Corresponding author: Ubaid Illahi (ubaidllahi@nitsri.ac.in) 
perspective. To approach sustainable mobility, it is important to incorporate the attributes associated with interactions as well as the overlap of the three sustainability pillars, namely environmental, social, and economic.

Owing to the complexity of the transportation system, the decisions towards its sustainability are, however, difficult to take. Indicators are useful in this context. From a sustainability viewpoint, the use of indicators is useful in quantifying, assessing, and measuring the efficiency of transportation systems. Setting benchmarks, recognizing developments and trends, forecasting snags, assessing alternatives, setting success goals, and evaluating a specific dominion or entity are all made easier with indicators (Litman, 2007). However, a large number of indicators are needed to capture the multi-dimensional nature of transportation, which is both cumbersome and challenging for decision-makers. As a result, combining indicators into an index is a good idea (Reisi et al., 2014). The literature (OECD, 2008) contains methods for constructing indices. The main steps in the construction of an index are usually normalization, weighting, and aggregation. There are a variety of normalization, weighting, and aggregation approaches available, each with its own set of benefits and drawbacks (Gan et al., 2017). As a result, method selection necessitates careful consideration.

The aim of this article is to develop a model for transport sustainability performance evaluation. The novelty of the proposed methodological framework is that it utilizes a combination of statistics-based, machine learning-based, and equal weighting-based approaches. The weighting and aggregation are done at three different levels using Principal Component Analysis (PCA), Fuzzy logic, and method of equal weights, respectively, to obtain an index. As compared to other approaches, this technique of using a variety of techniques minimizes the drawbacks. To validate the proposed model and check its robustness, it was applied to four metropolitan cities of India namely Delhi, Mumbai, Kolkata, and Chennai, as the case study. Since transport sustainability challenges are more apparent in developing and emerging countries, this case study was chosen. 116 indicators were developed based on the homogeneous data availability and accessibility for these metropolitan cities. These indicators were divided among ten classes relating to three sustainability pillars: environmental, social, and economic. The final index was computed for all the four metropolitan cities which were ranked and further analyzed for identifying the deficiencies and/or strengths within their transportation system.

\section{Literature Review}

A growing number of challenges related to transport sustainability has resulted in an increase in performance evaluation research across the globe (Illahi and Mir, 2021). Some research is based on a single aspect of it (Husain, Abdullah and Kuman, 2002), while some others are based on multiple aspects of it (Mahdinia and Habibian, 2017). As transport systems are becoming more and more complex, big data sets need to be handled. This has invited the use of dimension reduction techniques, owing to its benefits in dealing with big data sets without causing the issues of interpretability (Horiuchi et al., 2017).

Every organization and/or Department of Transportation (DOT) is unique in its own way, possessing several strengths as well as weaknesses. Therefore, the goals towards achieving sustainable transportation may vary (Jeon and Amekudzi, 2005). Setting up a suitable framework is therefore useful. Nevertheless, some well-established frameworks exist in the literature (TERM, 2011), some researchers have also contributed to this field. 
For example, Evaluative and Logical Approach to Sustainable Transport Indicator Compilation (ELASTIC) was proposed by Castillo and Pitfield (2010). This framework was useful in extracting the 15 most-suitable indicators from a set of 233 indicators. Pei et al. (2010) analyzed five performance evaluation frameworks and identified seven attributes for the development of indicators. Cornet and Gudmundsson (2015) proposed a metaframework by reviewing several sustainable transportation frameworks. It identified three critical elements that a framework should possess 1) conceptualization, 2) operationalization, and 3) utilization. Similarly, key issues and selection criteria for frameworks and indicators are discussed in detail in a book by Gudmundsson et al. (2016).

There are several number of approaches to weight and aggregate the indicators available in the literature. The choice of these methods is, however, to be given due consideration. Gan et al. (2017) studied several weighting and aggregation methods and proposed a process-oriented approach for selecting a suitable one. Researchers have used various weighting and aggregation methods to develop sustainable transportation indices across the globe at the local, national as well as global levels.

Apart from the methods discussed, Artificial Intelligence (AI) and machine learning tools were also used to determine the efficiency of transportation systems. Awasthi et al. (2011) and Sarkar et al. (2012), for example, investigated the use of Fuzzy Logic in the analysis of transportation systems. Similarly, Rajak et al. (2016) used Fuzzy Logic to develop a model for evaluating the efficiency of a transportation system. Their model was used to shortlist 20 deficiencies in a transportation system that needed urgent attention. Using Fuzzy Multi-Criteria Decision-Making (FMCDM) approach, the urban freight transport of Rio de Janeiro was evaluated by Bandeira et al., (2018). Likewise, Kumar and Anbanandam (2019) formulated a methodology that led to the development of an index related to freight transport. They used Fuzzy Logic to combine 74 indicators in their analysis.

The following points were observed based on the literature review: (1) the selection of normalization, weighting, and aggregation approaches influences the composite indicator which is consistent with Danielis et al. (2018), (2) Most of the transportation-related index development studies used equal weighting approach or AHP which is consistent with Gan et al. (2017), (3) In most of the cases, a fewer number of indicators have been used which is in line with Mahdinia et al. (2018), and (4) Lastly, a combination of various weighting techniques would be useful compared to the single weighting technique. Therefore, this study proposes a multi-stage and multi-tool hybrid model (MMHM) by utilizing a combination of PCA, Fuzzy Logic, and equal weighting approach at three different levels to produce an index called Sustainable Mobility Index (SMI). The proposed model not only takes into account the variance in the indicators but also converts the experts' opinion to a mathematical formula and thus overcomes the limitations of the previous studies. The index, so developed is capable of considering as many indicators as possible without the issues of interpretability.

\section{Methodology}

The steps of the proposed multi-stage and multi-tool hybrid model (MMHM) for performance evaluation of sustainable mobility are presented in a flow chart (see Figure 1). Broadly, these steps are divided into three levels. At Level 1, the indicators are subjected to normalization followed by PCA and linear aggregation. This results in obtaining statistical sub-indices for each class. At Level 2, fuzzy sub-indices are obtained 
for each sustainability pillar. Finally, at Level 3, Sustainable Mobility Index (SMI) is obtained. These steps are explained in detail in the subsequent sub-sections.

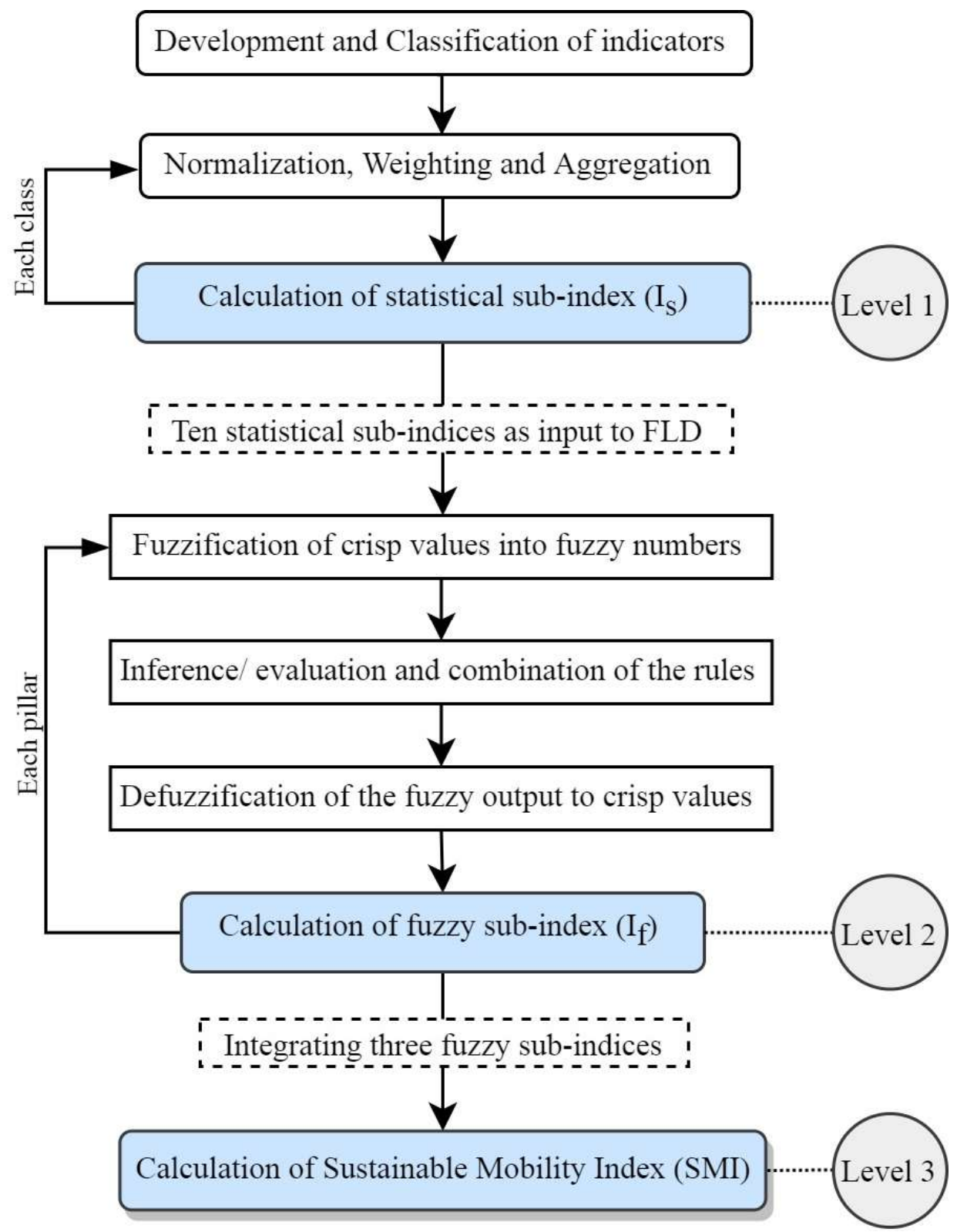

Figure 1: Flowchart for performance evaluation of sustainable mobility using MMHM.

\subsection{Sustainable mobility indicators}

In this study, the quantification of sustainable mobility was done through indicators. The indicators that were developed in this study were divided into ten classes. Each class corresponds to either of the sustainability pillars 1) Environmental, 2) Social, and 3) Economic. The details of indicators corresponding to the ten classes under three sustainability pillars are enlisted in Tables $1-3$. 
Table 1: Classes and indicators corresponding to the Environmental sustainability pillar.

\begin{tabular}{|c|c|c|}
\hline Pillar & Environmental & \\
\hline \multirow[t]{9}{*}{ Class } & Vehicular emissions (C1) & \\
\hline & Indicator & Impact \\
\hline & Annual (An.) GHG emissions by transportation per capita & $\Downarrow$ \\
\hline & An. GHG emissions by transportation per area & $\downarrow$ \\
\hline & $\begin{array}{l}\text { An. GHG emissions by transportation per total energy consumption of major petroleum } \\
\text { products by transportation }\end{array}$ & $\downarrow$ \\
\hline & An. GHG emissions by transportation per total Vehicle Kilometres Travelled (VKT) & $\downarrow$ \\
\hline & An. average density of $\mathrm{PM}_{10}$ in $\mu \mathrm{g} / \mathrm{m}^{3}$ & $\downarrow$ \\
\hline & An. average density of $\mathrm{SO}_{2}$ in $\mu \mathrm{g} / \mathrm{m}^{3}$ & $\downarrow$ \\
\hline & An. average density of $\mathrm{NO}_{2}$ in $\mu \mathrm{g} / \mathrm{m}^{3}$ & $\downarrow$ \\
\hline \multirow[t]{13}{*}{ Class } & Non-renewable energy consumption by transportation $(\mathrm{C} 2)$ & \\
\hline & Indicator & Impact \\
\hline & An. energy consumption of major petroleum products by transportation per capita & $\Downarrow$ \\
\hline & An. energy consumption of major petroleum products by transportation per area & $\downarrow$ \\
\hline & An. energy consumption of major petroleum products by transportation per an. VKT & $\downarrow$ \\
\hline & Percent consumption of diesel fuel in the transportation sector & $\downarrow$ \\
\hline & $\begin{array}{l}\text { An. energy consumption of major petroleum products by transportation per Gross State } \\
\text { Domestic Product (GSDP) }\end{array}$ & $\downarrow$ \\
\hline & $\begin{array}{l}\text { An. energy consumption of major petroleum products by transportation per total number } \\
\text { of vehicles }\end{array}$ & $\downarrow$ \\
\hline & Percent length of railway routes electrified per total length of railway routes & $\uparrow$ \\
\hline & Percentage of an. consumption of diesel by public transportation modes & 个 \\
\hline & Percentage of an. consumption of diesel by private transportation modes & $\downarrow$ \\
\hline & $\begin{array}{l}\text { Percentage of an. consumption of petrol by public transportation modes including shared } \\
\text { taxis and three-wheelers }\end{array}$ & 个 \\
\hline & $\begin{array}{l}\text { Percentage of an. consumption of petrol by private transportation modes including cars } \\
\text { and two-wheelers }\end{array}$ & $\downarrow$ \\
\hline \multirow[t]{23}{*}{ Class } & Land-use in transportation infrastructure (C3) & \\
\hline & Indicator & Impact \\
\hline & Total length of roads per capita & $\downarrow$ \\
\hline & The total length of roads per area & $\downarrow$ \\
\hline & The total length of roads per an. VKT & $\downarrow$ \\
\hline & Percentage of total length of NHs per total length of roads & $\downarrow$ \\
\hline & Total length of National Highways (NHs) per capita & $\downarrow$ \\
\hline & Total length of NHs per area & $\downarrow$ \\
\hline & Total length of NHs per an. VKT & $\downarrow$ \\
\hline & Percentage of total length of State Highways (SHs) per total length of roads & $\downarrow$ \\
\hline & Total length of SHs per capita & $\downarrow$ \\
\hline & Total length of SHs per area & $\downarrow$ \\
\hline & Total length of SHs per an. VKT & $\downarrow$ \\
\hline & Percentage of total length of urban roads per total length of roads & $\downarrow$ \\
\hline & Total length of urban roads per capita & $\downarrow$ \\
\hline & Total length of urban roads per area & $\downarrow$ \\
\hline & Total length of urban roads per an. VKT & $\downarrow$ \\
\hline & $\begin{array}{l}\text { Percentage of total length of other Public Works Department (PWD) roads per total length } \\
\text { of roads }\end{array}$ & $\downarrow$ \\
\hline & Total length of other PWD Roads per capita & $\downarrow$ \\
\hline & Total length of other PWD Roads per area & $\downarrow$ \\
\hline & Total length of other PWD Roads per an. VKT & $\downarrow$ \\
\hline & Percentage of total length of rural roads per total length of roads & $\downarrow$ \\
\hline & Total length of rural roads per capita & $\downarrow$ \\
\hline
\end{tabular}


Total length of rural roads per area

Total length of rural roads per an. VKT

Class Environmental efficiency of vehicles and renewable energy potential (C4)

Indicator Impact

Percentage of Compressed Natural Gas (CNG) filling stations to petrol filling stations

An. renewable energy potential per capita

An. renewable energy potential per total number of vehicles

An. renewable energy potential per an. VKT

An. renewable energy potential per an. energy consumption of major petroleum products by transportation

SRTUs fuel efficiency (km per litre of High-Speed Diesel (HSD)/ km per kg of CNG)

Table 2: Classes and indicators corresponding to Social sustainability pillar.

\begin{tabular}{|c|c|c|}
\hline Pillar & Social & \\
\hline \multirow[t]{26}{*}{ Class } & Safety of transport users (C5) & \\
\hline & Indicator & Impact \\
\hline & An. Reported Road Traffic Crashes (RRTCs) per capita & $\Downarrow$ \\
\hline & An. RRTCs per an. VKT & $\downarrow$ \\
\hline & An. RRTCs per total length of roads & $\downarrow$ \\
\hline & An. RRTCs per total number of vehicles & $\downarrow$ \\
\hline & An. RRTCs per total number of drivers with valid license & $\downarrow$ \\
\hline & An. Reported Road Traffic Fatalities (RRTFs) per capita & $\downarrow$ \\
\hline & An. RRTFs per an. VKT & $\downarrow$ \\
\hline & An. RRTFs per total length of roads & $\downarrow$ \\
\hline & An. RRTFs per total number of vehicles & $\downarrow$ \\
\hline & An. RRTFs per total number of drivers with valid license & $\downarrow$ \\
\hline & An. Reported Serious Injuries (RSI) in road traffic per capita & $\downarrow$ \\
\hline & An. RSIs in road traffic per an. VKT & $\downarrow$ \\
\hline & An. RSIs in road traffic per total length of roads & $\downarrow$ \\
\hline & An. RSIs in road traffic per total number of vehicles & $\downarrow$ \\
\hline & An. RSIs in road traffic per total number of drivers with valid license & $\downarrow$ \\
\hline & An. Reported Minor Injuries (RMIs) in road traffic per capita & $\downarrow$ \\
\hline & An. RMIs in road traffic per an. VKT & $\downarrow$ \\
\hline & An. RMIs in road traffic per total length of roads & $\downarrow$ \\
\hline & An. RMIs in road traffic per total number of vehicles & $\downarrow$ \\
\hline & An. RMIs in road traffic per total number of drivers with valid license & $\downarrow$ \\
\hline & An. Non-motorized traffic fatalities per total recorded RTFs & $\downarrow$ \\
\hline & An. public transportation fatalities per total number of buses & $\downarrow$ \\
\hline & An. accident cases in Railways per total length of railway track & $\downarrow$ \\
\hline & An. fatalities in Railways per total length of railway track & $\downarrow$ \\
\hline \multirow[t]{11}{*}{ Class } & Access to transport modes and conveniences (C6) & \\
\hline & Indicator & Impact \\
\hline & Total number of registered vehicles per capita & 个 \\
\hline & Total number of registered vehicles per total number of drivers with valid driving license & $\uparrow$ \\
\hline & Total number of registered vehicles per total number of households & 个 \\
\hline & Total number of fuel filling stations per total length of roads & $\uparrow$ \\
\hline & An. inter-state work trips per capita & $\uparrow$ \\
\hline & An. inter-state work trips per area & $\uparrow$ \\
\hline & Domestic tourist visits per capita & $\uparrow$ \\
\hline & Domestic tourist visits per area & $\uparrow$ \\
\hline & Total length of railway roads per total length of running railway track & $\uparrow$ \\
\hline
\end{tabular}


Total number of passenger trips by scheduled flight operations per capita

Total number of passenger trips by scheduled flight operations per area

Total number of passenger trips by scheduled flight operations per total number of households

\begin{tabular}{llc}
\hline Class & Public transit efficacy (C7) & Impact \\
\hline Indicator & $\uparrow$ \\
SRTUs staff/bus ratio & $\uparrow$ \\
Percentage of SRTUs occupancy ratio & $\uparrow$ \\
Passengers carried by SRTUs per bus per day & $\uparrow$ \\
SRTUs passenger kilometres offered & $\uparrow$ \\
SRTUs passenger kilometres performed & $\uparrow$
\end{tabular}

Table 3: Classes and indicators corresponding to the Economic sustainability pillar.

\begin{tabular}{|c|c|c|}
\hline Pillar & Economic & \\
\hline \multirow[t]{18}{*}{ Class } & Transport costs and expenses (C8) & \\
\hline & Indicator & Impact \\
\hline & An. SRTUs expenditure per capita & $\downarrow$ \\
\hline & An. SRTUs expenditure per GSDP & $\downarrow$ \\
\hline & An. SRTUs expenditure per GSDP per capita & $\downarrow$ \\
\hline & Funds allocated under economic importance and inter-state connectivity per capita & $\downarrow$ \\
\hline & Funds allocated under economic importance and inter-state connectivity per GSDP & $\downarrow$ \\
\hline & $\begin{array}{l}\text { Funds allocated under economic importance and inter-state connectivity per GSDP per } \\
\text { capita }\end{array}$ & $\downarrow$ \\
\hline & Funds released under economic importance and inter-state connectivity per capita & $\downarrow$ \\
\hline & Funds released under economic importance and inter-state connectivity per GSDP & $\downarrow$ \\
\hline & $\begin{array}{l}\text { 97. Funds released under economic importance and inter-state connectivity per GSDP per } \\
\text { capita }\end{array}$ & $\downarrow$ \\
\hline & An. accrual allocation of funds under Central Road Fund (CRF) schemes per capita & $\downarrow$ \\
\hline & An. accrual allocation of funds under CRF schemes per GSDP & $\downarrow$ \\
\hline & An. accrual allocation of funds under CRF schemes per GSDP per capita & $\downarrow$ \\
\hline & An. accrual release of funds under CRF schemes per capita & $\downarrow$ \\
\hline & An. accrual release of funds under CRF schemes per GSDP & $\downarrow$ \\
\hline & An. accrual release of funds under CRF schemes per GSDP per capita & $\downarrow$ \\
\hline & Allocation for Repair and Maintenance of NHs per total length of NHs & $\downarrow$ \\
\hline \multirow[t]{7}{*}{ Class } & Revenue generated from transport (C9) & \\
\hline & Indicator & Impact \\
\hline & An. SRTUs revenue per capita & $\uparrow$ \\
\hline & An. SRTUs revenue per GSDP & $\uparrow$ \\
\hline & An. SRTUs revenue per GSDP per capita & $\uparrow$ \\
\hline & Revenue from rate of taxes levied on petrol & $\uparrow$ \\
\hline & Revenue from rate of taxes levied on diesel & $\uparrow$ \\
\hline \multirow[t]{9}{*}{ Class } & Economic efficiency of transportation system $(\mathrm{C} 10)$ & \\
\hline & Indicator & Impact \\
\hline & Percentage of SRTUs fleet utilization & $\uparrow$ \\
\hline & SRTUs staff productivity measured in km per staff per day & 个 \\
\hline & SRTUs vehicle productivity measured in $\mathrm{km}$ per bus per day & $\uparrow$ \\
\hline & An. freight shipment at airports per capita & $\uparrow$ \\
\hline & An. freight shipment at airports per area & $\uparrow$ \\
\hline & Freight train kilometres performed per capita & $\uparrow$ \\
\hline & Freight train kilometres performed per area & $\uparrow$ \\
\hline
\end{tabular}




\subsection{Indicator normalization}

Based on the guidelines provided in the literature (Illahi and Mir, 2020), min-max method was used to normalize the indicators (refer to Eq. (1) and Eq. (2)).

$$
\begin{aligned}
& N V_{S M I}^{+}=\frac{I_{x}^{+}-I_{\min }^{+}}{I_{\max }^{+}-I_{\min }^{+}} \\
& N V_{S M I}^{-}=\frac{I_{\max }^{-}-I_{x}^{-}}{I_{\max }^{-}-I_{\min }^{-}}
\end{aligned}
$$

where, $I_{\min }^{+}$and $I_{\max }^{+}$are the minimum and maximum values of positive indicators denoted by $I_{x}^{+} ; I_{\min }^{-}$and $I_{\max }^{-}$are the minimum and maximum values of negative indicators denoted by $I_{x}^{-} ; N V_{S M I}^{-}$and $N V_{S M I}^{+}$are the normalized values of $I_{x}^{-}$and $I_{x}^{+}$ respectively.

\subsection{Applying PCA to normalized indicators}

This study utilized a (statistical) dimension reduction tool called PCA (refer to Eq. (3), Eq. (4), and Eq. (5)) to weight the normalized indicators. To check the feasibility of applying PCA, two tests should be performed (Reisi et al., 2014). These tests include 1) data redundancy test on correlation matrix and 2) Kaiser-Meyer-Olkin test. After the indicators successfully passed these tests, latent factors were extracted. A series of coefficients called factor loadings affect each latent factor. These factor loadings determined the correlation between each indicator and the latent factor that includes eigen-values and eigen-vectors. According to Mahdinia et al. (2018), eigen-values greater than one are typically selected since including a latent factor that explains less uncertainty than the indicator itself is illogical.

$$
\begin{aligned}
& w_{i, l d p}=\frac{\left(C_{i, l d p}\right)^{2}}{E V_{l d p}} \text { such that } i \in i_{d}, l \in L_{d}, q \in Q_{p}, p \in P \\
& P C I_{l d p}=\sum_{i}\left\{\left(w_{i, l d p}\right)\left(N V_{i, l d p}\right)\right\} \text { such that } i \in i_{d}, l \in L_{d}, d \in D_{p}, p \in P \\
& v_{l q p}=\frac{E V_{l q p}}{\sum_{l d} E V_{l q p}} \text { such that } l \in L_{d}, d \in D_{p}, p \in P
\end{aligned}
$$

where, $w_{i, l d p}$ represents the weight assigned to indicator corresponding to latent factor $(l)$, divided class $(d)$ and sustainability pillar $(p), C_{i, l d p}$ is the principal component, $E V_{l d p}$ is the eigen-value, $P C I_{l d p}$ is the principal combined index, $N V_{i, l d p}$ is the normalized value of an indicator.

\subsection{Aggregation of weighted indicators}

The aggregation of indicators that were weighted in the previous step was done using the linear aggregation method (refer to Eq. (6)) to obtain a statistical sub-index $\left(I_{s}\right)$, representing the characteristic of each class $(d)$.

$$
I_{s}=\sum_{l}\left\{\left(v_{l d p}\right)\left(P C I_{l d p}\right)\right\} \text { such that } l \in L_{d}, d \in D_{p}, p \in P
$$


where, $v_{l d p}$ represents the weight given to $P C I_{l d p}$.

\subsection{Applying Fuzzy weighting to statistical sub-indices}

Many researchers argue that involving experts opinions' within the evaluation models is both important as well as critical. Fuzzy logic has been found to be helpful in assessing sustainability because it converts expert views into a quantitative formula (Rossi, Gastaldi and Gecchele, 2013). Since in this study, MMHM is aimed at transport sustainability performance evaluation, to weight the statistical sub-indices, expert opinion was incorporated using Fuzzy Logic.

The first step in applying Fuzzy Logic is to model Fuzzy Logic Designer (FLD). The FLD was modeled for each sustainability pillar as shown in Figures 2. In FLD, the statistical sub-indices were the inputs. FLD model variables include the following: 1) fuzzy inference system- "Mamdani", 2) defuzzification method- "centroid", 3) AND method and implication method- minimum, 4) OR method and aggregation methodmaximum, and 5) input/ output range [0,1]. Triangular Membership Function (see Figure 3 ) was used for inputs/ outputs on the basis of the literature (Rajak et al., 2016). The next step was to define linguistic variables in Membership Function Editor (MFE). Table 4 shows the fuzzy numbers for each of the five defined linguistic variables. The rule-base was developed by means of multiple rounds of discussion with transportation experts. This resulted in the development of three fuzzy sub-indices $\left(I_{f}\right)$.

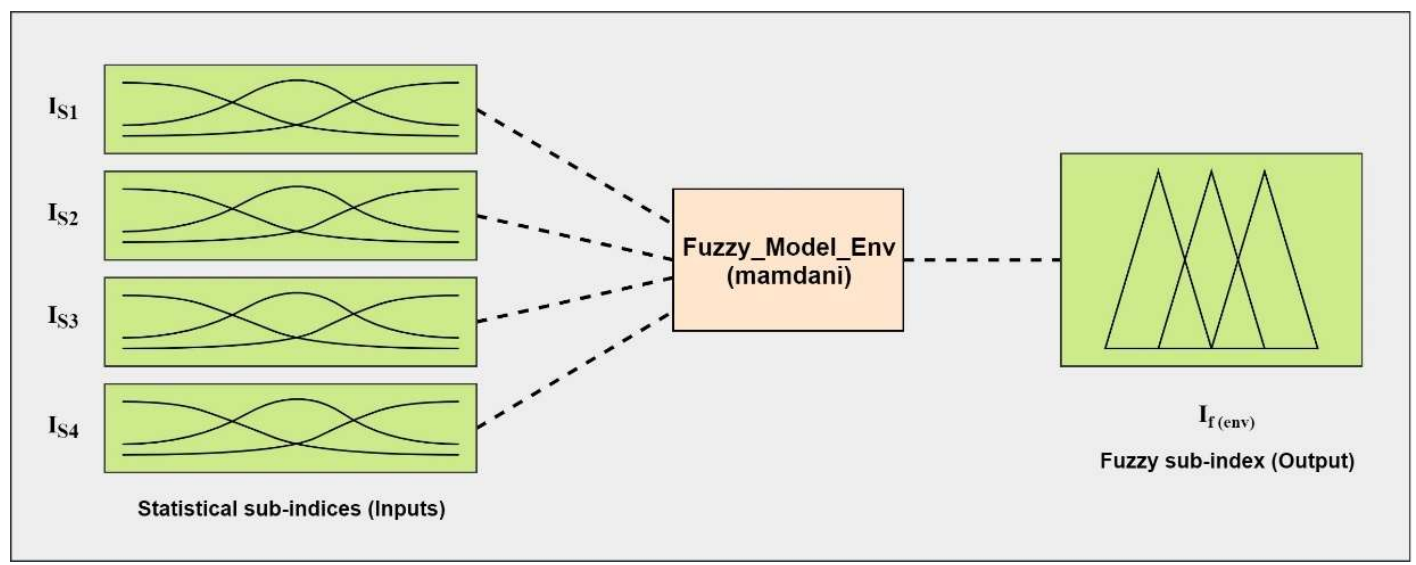

(a) FLD for Environmental pillar of sustainability

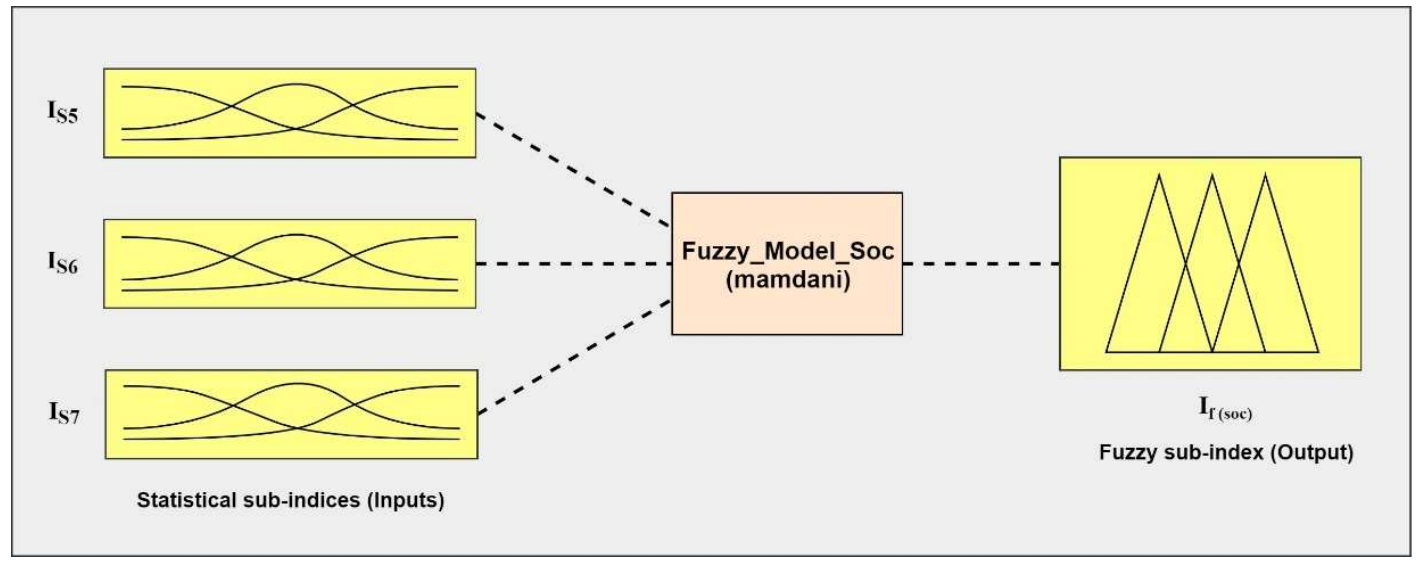

(b) FLD for Social pillar of sustainability 


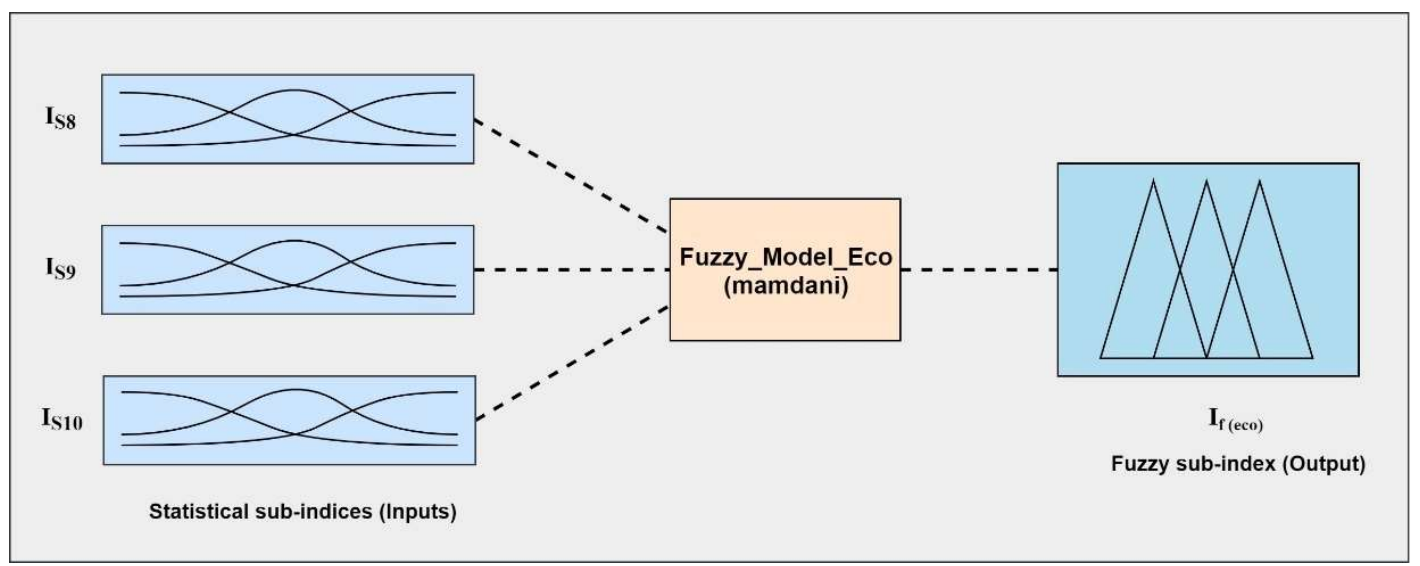

(c) FLD for Economic pillar of sustainability

Figure 2. Developed FLDs corresponding to three sustainability pillars.

\subsection{Final integration of fuzzy sub-indices}

It is recommended in the literature (Zito and Salvo, 2011) that equal weights must be assigned to the three sustainability pillars. Therefore, Sustainability Mobility Index (SMI) was obtained by weighting three fuzzy sub-indices using the equal weighting method (refer Eq. (7)).

$$
S M I=\frac{\sum p\left\{(w *)\left(I_{f}\right)\right\}}{3} \text { such that, } f \in P, w^{*}=1
$$

where, $w^{*}$ is the weight applied to each fuzzy sub-index.

Table 4: Linguistic variables defined in MFE.

\begin{tabular}{|c|c|c|c|c|}
\hline Variable Name & Label & \multicolumn{3}{|c|}{ Fuzzy number } \\
\hline Relatively Best & A & {$[0.75$} & 1.00 & $1.00]$ \\
\hline Relatively Good & B & {$[0.50$} & 0.75 & $1.00]$ \\
\hline Relatively Average & $\mathrm{C}$ & {$[0.25$} & 0.50 & $0.75]$ \\
\hline Relatively Bad & $\mathrm{D}$ & {$[0.00$} & 0.25 & $0.50]$ \\
\hline Relatively Worst & $\mathrm{E}$ & {$[0.00$} & 0.00 & $0.25]$ \\
\hline
\end{tabular}

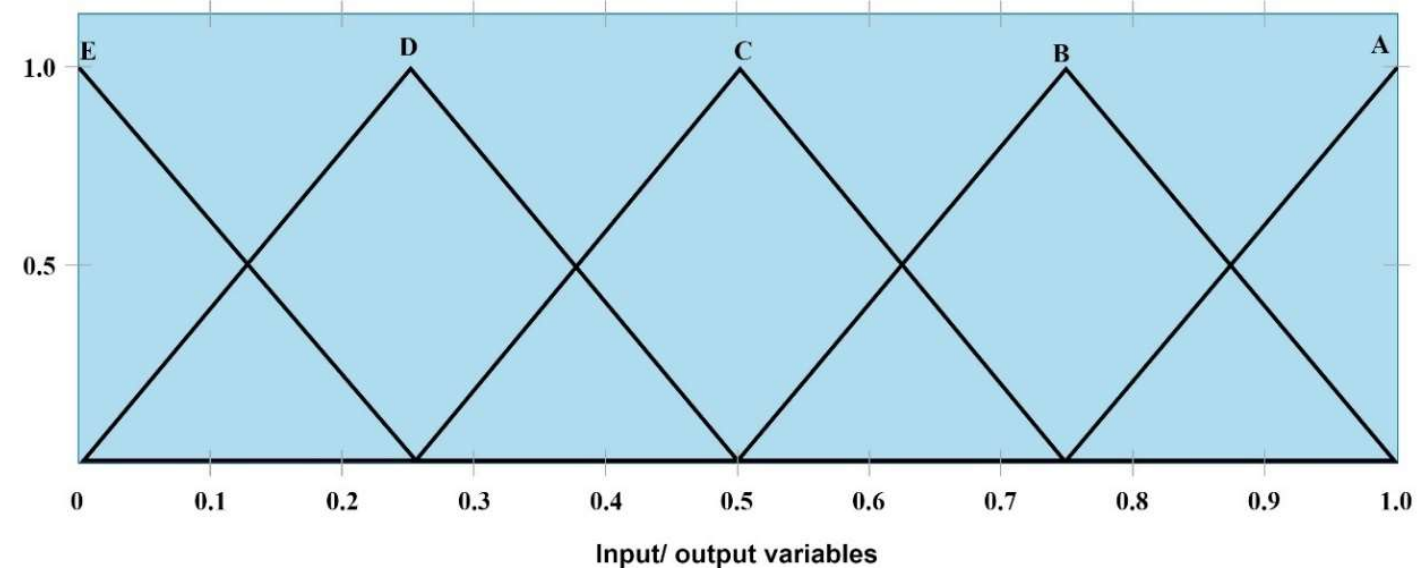

Figure 3. Triangular Membership function assigned to input and output parameters. 


\section{Case Study}

The proposed performance evaluation model was tested on four metropolitan cities of India. These cities include Delhi (North), Kolkata (East), Mumbai (South-west), and Chennai (South).

\subsection{Data collection to develop sustainable mobility indicators}

The latest data for the study areas was obtained for the year 2015-16. Data was collected from the OGDP-India (2016), Datanet-India (2016), and Ministry of Statistics and Program Implementation (MoSPI, 2016). In order to maintain consistency across the indicators, data obtained from Census-2011 had to be extrapolated. It is noteworthy that the "geometric rate of increase" method of extrapolation was used in this study.

116 indicators divided into ten classes were developed based on the available data and recommendations presented in the literature. These indicators were utilized to assess the efficiency of transportation systems in terms of sustainability across the four metropolitan cities. The detailed list of 116 indicators and the impact of each of these on transport sustainability is presented in Tables 1-3. The indicators were normalized on the basis of positive or negative impact on transport sustainability which was followed by weighting and aggregation.

\section{Results and Discussion}

The procedure (as explained in Section 3) was repeated for four metropolitan cities namely Delhi, Mumbai, Chennai, and Kolkata to obtain the Sustainability Mobility Index (SMI) for each city. The PCA resulted in ten statistical sub-indices $\left(I_{S 1}\right.$ to $\left.I_{S 10}\right)$ while as in the next step, the application of Fuzzy Logic produced three fuzzy sub-indices ( $I_{f(e n v)}, I_{f(s o c)}$ and $\left.I_{f(e c o)}\right)$ for all the four cities (refer to Table 5). The fuzzy sub-indices were further reduced to obtain SMI. The SMI values obtained for all the cities were plotted on a radar diagram (see Figure 4). Relatively, the metropolitan city with a higher value of SMI shows better performance of transportation system as far as sustainability is concerned. The results showed that Chennai $(S M I=0.643)$ possessed better transport sustainability than Mumbai $(S M I=0.564)$ followed by Kolkata $(S M I=0.542)$ and Delhi $(S M I=0.533)$.

Table 5: Computed sub-indices for the four metropolitan cities of India.

\begin{tabular}{|c|c|c|c|c|c|c|c|c|c|c|}
\hline \multirow{2}{*}{ City } & \multicolumn{10}{|c|}{ Statistical sub-indices } \\
\hline & $I_{S I}$ & $I_{S 2}$ & $I_{S 3}$ & $I_{S 4}$ & $I_{S 5}$ & $I_{S 6}$ & $I_{S 7}$ & $I_{S 8}$ & $I_{S 9}$ & $I_{S 10}$ \\
\hline Chennai & 0.762 & 0.684 & 0.766 & 0.197 & 0.661 & 0.250 & 0.850 & 0.845 & 0.293 & 0.526 \\
\hline Mumbai & 0.682 & 0.638 & 0.693 & 0.131 & 0.816 & 0.151 & 0.595 & 0.828 & 0.361 & 0.342 \\
\hline Kolkata & 0.758 & 0.669 & 0.746 & 0.115 & 0.806 & 0.171 & 0.277 & 0.855 & 0.163 & 0.393 \\
\hline \multirow[t]{3}{*}{ Delhi } & 0.346 & 0.426 & 0.828 & 0.192 & 0.757 & 0.507 & 0.484 & 0.884 & 0.186 & 0.568 \\
\hline & \multicolumn{10}{|c|}{ Fuzzy sub-indices } \\
\hline & \multicolumn{4}{|c|}{$I_{f(e n v)}$} & \multicolumn{3}{|c|}{$I_{f(s o c)}$} & \multicolumn{3}{|c|}{$I_{f(e c o)}$} \\
\hline Chennai & \multicolumn{4}{|c|}{0.563} & \multicolumn{3}{|c|}{0.743} & \multicolumn{3}{|c|}{0.623} \\
\hline Mumbai & \multicolumn{4}{|c|}{0.619} & \multicolumn{3}{|c|}{0.499} & \multicolumn{3}{|c|}{0.574} \\
\hline Kolkata & \multicolumn{4}{|c|}{0.622} & \multicolumn{3}{|c|}{0.397} & \multicolumn{3}{|c|}{0.608} \\
\hline Delhi & \multicolumn{4}{|c|}{0.494} & \multicolumn{3}{|c|}{0.483} & \multicolumn{3}{|c|}{0.622} \\
\hline
\end{tabular}




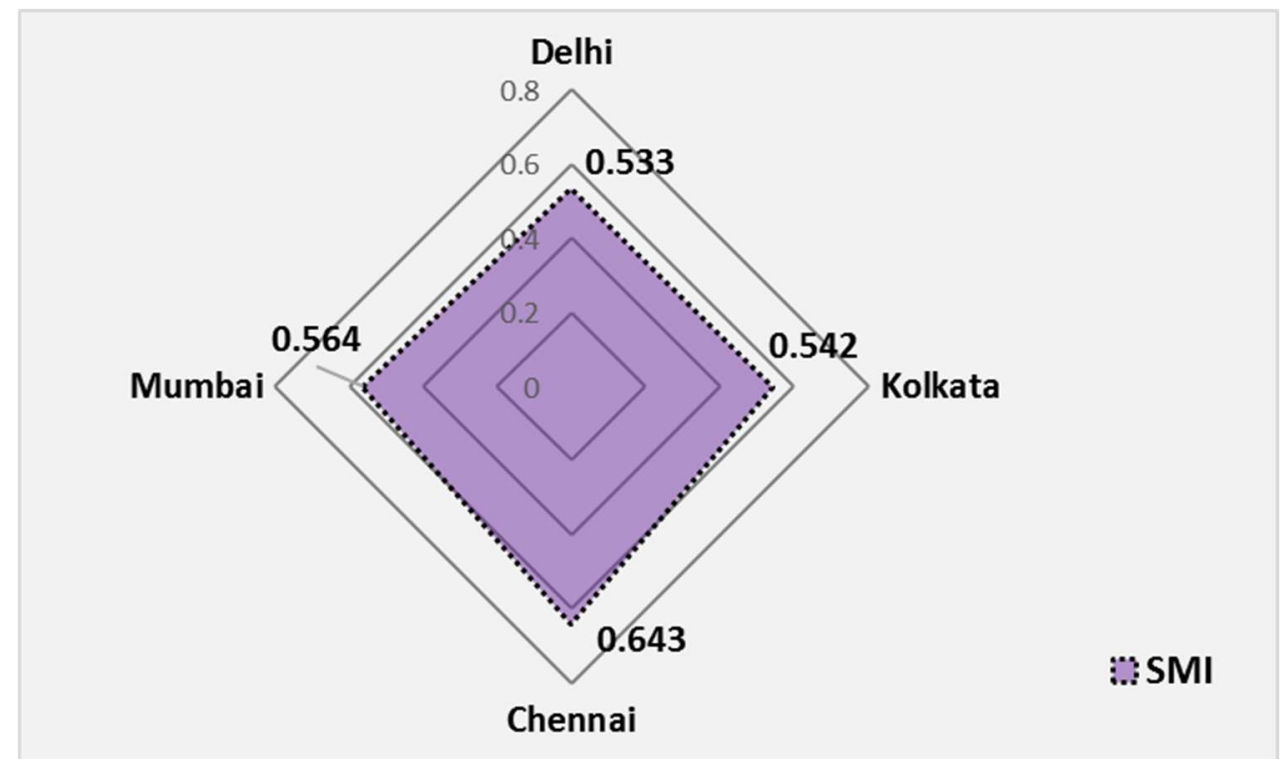

Figure 4. Radar plot showing Sustainable Mobility Indices (SMIs) of four metropolitan cities of India.

The proposed MMHM is flexible to accommodate any number of indicators. In other words, it has no restriction on the use of the number of indicators. Despite this, the output is in the form of a composite indicator (or index), which provides a single snapshot of a wider and complicated problem relating to the overall efficiency of transportation systems in terms of sustainability. This attribute would be helpful to policymakers, and other stakeholders who do not have a deep understanding of the issue. It will aid in recognizing and tracking the performance of transport systems in an integrated way. It would be helpful in strengthening the capabilities of the transportation system while improving the deficiencies, thus moving it towards sustainability. Apart from this, the proposed model can be broken down into its fundamental constituents i.e. indicators. This is argued to be the requirement of a robust framework as stated by Gudmundsson et al. (2016). This can be understood by means of the following examples. Analyzing the best-performing metropolitan city i.e. Chennai, the statistical-weighted index $\left(I_{S 7}\right)$ corresponding to the seventh class- "Public transit efficacy" (C7) dominated when compared with the other three metropolitan cities (refer to Table 5). The further analysis, done at a finer scale shows that Chennai is the only metropolitan connected with seven SRTUs. This, in turn increases the efficiency the indicators relating to public transit system. It signifies that greater the public transit fleets, better the transport system sustainability performance. Contrarily, if the city with lowest SMI value i.e. Delhi is analyzed, statistical-weighted index corresponding to the first class, "Vehicular emissions" (C1) is found to be the main issue (refer to Table 5). Further evaluating it, the $\mathrm{PM}_{2.5}$ and $\mathrm{PM}_{10}$ concentrations are high leading to increasing the negative impact on the related indicators. These results and interpretations are in line with the report by World Health Organization (WHO, 2016). Other root causes of transportation sustainability may also be investigated and identified using the proposed model. As a result, transport evaluators and planners will find it beneficial. It is quite worth noting that even the best-performing metropolitan city can be lacking in some aspects, which transport authorities would like to invest to improve. Similarly, transport authorities might shift their focus from certain aspects of a weak metropolitan city that shows relatively better performance. This discussion highlighted 
some important points that can be summed up in the following: (1) SMI is a useful communication tool for evaluating transportation system efficiency because it makes the comparisons simple and fast, (2) the selection of relevant criteria and approaches, as well as the ability to disintegrate the index into its core components, make aggregation of indicators useful, (3) since a large number of indicators is complex and cumbersome for decision makers due to their difficult interpretation, it is helpful to combine various indicators into a an index, and (4) hybrid techniques exploit the merits of individual techniques while minimizing the demerits if framed properly.

\section{Conclusions}

The aim of the article was to develop an integrated model for evaluating the sustainability performance of transportation systems. In this line, a multi-stage and multitool hybrid model (MMHM) was proposed that evaluates the transportation system by utilizing a combination of statistics-based, machine learning-based, and equal weightingbased approaches. The proposed framework was based on pillars, classes, and indicators. To verify the robustness of the proposed framework, it was applied to four metropolitan cities of a developing nation-India. On the basis of homogenous data availability as well as accessibility, 116 indicators were developed. These indicators were divided into ten classes. The ten classes were categorized into Environmental, Social and Economic sustainability pillars. To analyze the indicators comparatively, they were normalized using the min-max normalization method. Then the weighting and aggregation were done in three different levels. The merits of different weighting methods are accounted for in an optimized manner using a combination of statistical tool (PCA), machine learning tool (Fuzzy logic), and method of equal weights. Thus, it overcomes the limitations over the other studies which utilized a single tool. The index obtained from the proposed MMHM, on one hand, considers the complexity of the pillars and classes. On the other hand, it simplifies the performance evaluation of transport systems and simplifies interpretability. It has been demonstrated by applying MMHM to a case study in which the output (SMI) was used to rank and compare India's four metropolitan cities. MMHM will, therefore, be useful for various transport authorities and stakeholders including decision-making bodies. Also, the proposed MMHM can be reverse engineered, thus signifying its diagnostic potential. This capability could be used by evaluators and policymakers to recognize, map, and improve the strengths of transportation systems while also working on their shortcomings, thus moving them towards sustainability.

\section{References}

Alonso, A., Monzón, A. and Cascajo, R. (2015) 'Comparative analysis of passenger transport sustainability in European cities', Ecological Indicators. Elsevier Ltd, 48, pp. 578-592. doi: 10.1016/j.ecolind.2014.09.022.

Awasthi, A., Chauhan, S. S. and Omrani, H. (2011) 'Application of fuzzy TOPSIS in evaluating sustainable transportation systems', Expert Systems with Applications. Elsevier Ltd, 38(10), pp. 12270-12280. doi: 10.1016/j.eswa.2011.04.005.

Bandeira, R. A. M. et al. (2018) 'A fuzzy multi-criteria model for evaluating sustainable urban freight transportation operations', Journal of Cleaner Production. Elsevier B.V., 184, pp. 727-739. doi: 10.1016/j.jclepro.2018.02.234.

Castillo, H. and Pitfield, D. E. (2010) 'ELASTIC - A methodological framework for identifying and selecting sustainable transport indicators', Transportation Research Part D: Transport and Environment. Elsevier Ltd, 15(4), pp. 179-188. doi: 
10.1016/j.trd.2009.09.002.

Cornet, Y. and Gudmundsson, H. (2015) 'Building a Metaframework for Sustainable Transport Indicators: Review of Selected Contributions', Transportation Research Record: Journal of the Transportation Research Board, 2531, pp. 103-112. doi: 10.3141/2531-12.

Danielis, R., Rotaris, L. and Monte, A. (2018) 'Composite indicators of sustainable urban mobility: estimating the rankings' frequency distribution combining multiple methodologies', International Journal of Sustainable Transportation, 12(5), pp. 380395. doi: 10.1080/15568318.2017.1377789.

Datanet-India (2016) Datanet India, Governemnet of India. Available at: http://datanetindia.com/aboutus.html (Accessed: 16 August 2018).

Gan, X. et al. (2017) 'When to use what: Methods for weighting and aggregating sustainability indicators', Ecological Indicators. Elsevier, 81(June), pp. 491-502. doi: 10.1016/j.ecolind.2017.05.068.

Gudmundsson, H. et al. (2016) Sustainable Transportation: Indicators, Frameworks and Performance Management. First. Springer Texts in Business and Economics. doi: 10.1007/978-3-662-46924-8.

Horiuchi, S. et al. (2017) 'Sustainable transportation pros, cons, and self-efficacy as predictors of 6-month stage transitions in a Chinese sample', Journal of Transport \& Health. Elsevier Ltd, 6(September), pp. 481-489. doi: 10.1016/j.jth.2017.05.363.

Husain, N., Abdullah, M. and Kuman, S. (2002) 'Evaluating public sector efficiency with data envelopment analysis (DEA): A case study in Road Transport Department, Selangor, Malaysia', Total Quality Management, 11(4-6), pp. 830-836. doi: 10.1080/09544120050008282.

Illahi, U. and Mir, M. S. (2020) 'Development of indices for sustainability of transportation systems: A review of state-of-the-art', Ecological Indicators. Elsevier, 118(June), pp. 1-18. doi: 10.1016/j.ecolind.2020.106760.

Illahi, U. and Mir, M. S. (2021) 'Sustainable Transportation Attainment Index: multivariate analysis of indicators with an application to selected states and National Capital Territory (NCT) of India', Environment, Development and Sustainability. Springer Netherlands, 23, pp. 3578-3622. doi: 10.1007/s10668-020-00734-w.

Jeon, C. M. and Amekudzi, A. (2005) 'Addressing Sustainability in Transportation Systems: Definitions, Indicators, and Metrics', Journal of Infrastructure Systems, 11(1), pp. 31-50. doi: 10.1061/(asce)1076-0342(2005)11:1(31).

Kumar, A. and Anbanandam, R. (2019) 'Development of social sustainability index for freight transportation system', Journal of Cleaner Production. Elsevier B.V., 210, pp. 77-92. doi: 10.1016/j.jclepro.2018.10.353.

Litman, T. (2007) 'Developing Indicators for Comprehensive and Sustainable Transport Planning', Transportation Research Record: Journal of the Transportation Research Board, pp. 10-15. doi: 10.3141/2017-02.

Mahdinia, I. et al. (2018) 'An indicator-based algorithm to measure transportation sustainability: A case study of the U.S. states', Ecological Indicators. Elsevier, 89(June), pp. 738-754. doi: 10.1016/j.ecolind.2017.12.019.

Mahdinia, I. and Habibian, M. (2017) 'Evaluating the Transportation System Performance Based on Efficiency, Effectiveness and Efficacy: A Case Study of the U.S. States', in Transportation Research Board 96th Annual Meeting. Washington DC, United States: Transportation Research Board (TRB). Available at: https://trid.trb.org/view/1439634. 
MoSPI (2016) Ministry of Statistics and Program Implementation, Government of India. Available at: http://www.mospi.gov.in/ (Accessed: 16 May 2018).

OECD (2008) Handbook of Constructing Composite Indicators: Methodology and user guide. JRC European Commission.

OGDP-India (2016) Open Government Data Platform India. Available at: https://data.gov.in/ (Accessed: 11 June 2018).

Pei, Y. et al. (2010) 'Performance Measurement Frameworks and Development of Effective Sustainable Transport Strategies and Indicators', Transportation Research Record: Journal of the Transportation Research Board, 2163(2163), pp. 73-80. doi: 10.3141/2163-08.

Rajak, S., Parthiban, P. and Dhanalakshmi, R. (2016) 'Sustainable transportation systems performance evaluation using fuzzy logic', Ecological Indicators, 71(December), pp. 503-513. doi: 10.1016/j.ecolind.2016.07.031.

Reisi, M. et al. (2014) 'Transport sustainability index : Melbourne case study', Ecological Indicators. Elsevier Ltd, 43(August), pp. 288-296. doi: 10.1016/j.ecolind.2014.03.004.

Rossi, R., Gastaldi, M. and Gecchele, G. (2013) 'Comparison of fuzzy-based and AHP methods in sustainability evaluation: A case of traffic pollution-reducing policies', European Transport Research Review, 5(1), pp. 11-26. doi: 10.1007/s12544-0120086-5.

Sarkar, A., Sahoo, G. and Sahoo, U. C. (2012) 'Application of Fuzzy Logic in Transport Planning', International Journal on Soft Computing, 3(2), pp. 1-21. doi: $10.5121 /$ ijsc. 2012.3201 .

TERM (2011) TERM 2011: transport indicators tracking progress towards environmental targets in Europe, EEA Report: Laying the foundations for greener transport. 7/2011. Copenhagen, Denmark. doi: 10.2800/82592.

WHO (2016) Air pollution, World Health Organization. World Health Organization. Available at: https://www.who.int/sustainable-development/transport/health-risks/airpollution/en/ (Accessed: 30 November 2018).

Zito, P. and Salvo, G. (2011) 'Toward an urban transport sustainability index: an European comparison', European Transport Research Review, 3(4), pp. 179-195. doi: 10.1007/s12544-011-0059-0. 